\title{
Collaboration and Co-Production of Knowledge in Healthcare: Opportunities and Challenges
}

\author{
Jo Rycroft-Malone $^{1^{*}}$, Christopher R. Burton ${ }^{1}$, Tracey Bucknall ${ }^{2,3}$, Ian D. Graham ${ }^{4,5}$, Alison M. Hutchinson ${ }^{2,3}$, \\ Dawn Stacey ${ }^{5}$
}

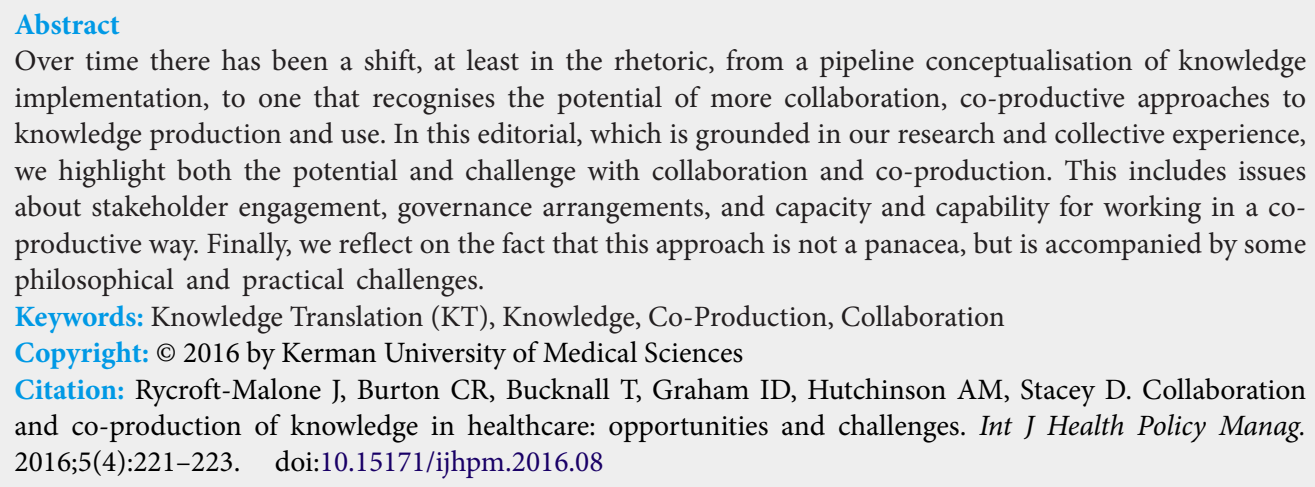

Over time there has been a shift, at least in the rhetoric, from a pipeline conceptualisation of knowledge implementation, to one that recognises the potential of more collaboration, co-productive approaches to knowledge production and use. In this editorial, which is grounded in our research and collective experience, we highlight both the potential and challenge with collaboration and co-production. This includes issues about stakeholder engagement, governance arrangements, and capacity and capability for working in a coproductive way. Finally, we reflect on the fact that this approach is not a panacea, but is accompanied by some philosophical and practical challenges.

Keywords: Knowledge Translation (KT), Knowledge, Co-Production, Collaboration Copyright: @ 2016 by Kerman University of Medical Sciences

Citation: Rycroft-Malone J, Burton CR, Bucknall T, Graham ID, Hutchinson AM, Stacey D. Collaboration and co-production of knowledge in healthcare: opportunities and challenges. Int $J$ Health Policy Manag. 2016;5(4):221-223. doi:10.15171/ijhpm.2016.08

Article History:

Received: 8 November 2015

Accepted: 26 January 2016

ePublished: 28 January 2016
$\mathrm{T}$ There has been increasing attention on social and interactional conceptualisations of knowledge implementation such that it has been suggested it might be 'time to drop the knowledge translation metaphor.' These authors argue that the term knowledge translation (KT) has come to represent the transfer of knowledge, which presupposes that knowledge production is separate from knowledge use. Consequently, the implementation challenge - whether evidence is used in practice, is frequently conceptualised as a 'gap.' Within this conceptualisation, the gap endures between those that produce the knowledge, and those that use it; between two communities and two cultures. ${ }^{2,3}$ Further, the assumption is that research gets produced, then packaged (in some way) to make it accessible to non-academics to increase the chances of it being used. Arguably this conceptualization is becoming an increasingly outdated perspective (not withstanding that the original definition of KT identifies one of the four elements of KT as knowledge exchange http://www.cihr-irsc.gc.ca/e/29418. html\#4.3). We are seeing the transfer paradigm challenged by the emergence of a more socially constructed and embedded view, in which knowledge is generated within its context of use, referred to variously as mode 2 knowledge production, ${ }^{4}$ engaged scholarship, ${ }^{5}$ interactive research, ${ }^{6}$ participatory research, ${ }^{7}$ and integrated $\mathrm{KT}^{8,9}$; all of which emphasise the coproduction of knowledge. In this editorial, we highlight both the potential and challenge of collaborative and co-productive approaches to knowledge production and use. In doing so, we propose that collaboration and co-production are inextricably linked in bringing together a plurality of knowledge sources together to address specific problems. ${ }^{10}$

The development of these approaches has been shaped by different political and other drivers, including empowerment of disenfranchised groups within interactive research, and in the resolution of real-world problems with engaged scholarship. However, we consider there to be shared ontological perspectives in different approaches to knowledge co-production, including the valuing of both codified and other forms of knowledge; the incremental nature of work within the knowledge endeavour; the acknowledgement of the importance of the complexity of the context in which this endeavour takes place; and meaningful stakeholder participation. These perspectives rely on authentic collaboration, partnership and engagement as the context for action, which in our experience of both practising and researching this approach, ${ }^{11,12}$ raises some issues we think are worth reflecting on given the gathering momentum behind collaborative models.

\section{Multiple Communities}

In contrast to considering two, homogenous communities (knowledge producers and knowledge users) being engaged in the endeavour, a collaborative approach involves and engages with potentially multiple knowledge user communities, including patients, carers, researchers, policy-makers, practitioners, and managers. This of course raises issues about power, politics and perceptions. These are not trivial issues, and will require careful navigation and negotiation to get to the point of being able to have productive conversations and engage in meaningful activity. Issues that need explication include, for example, the different perspective stakeholders will have about $(a)$ the value and relevance of research and $(b)$ respecting and understanding the contexts of the interpretation and application of research findings. Whilst there needs to be a sufficient dose of mutual respect, understanding each other's roles, contexts and contributions, 
individuals and groups are unlikely to engage in collaborative processes unless they can clearly see 'what is in it' for them. ${ }^{12}$ What incentivises a researcher (eg, meeting the needs of their career structure), will be different from what incentivises a practitioner (eg, wanting to make a difference, wanting to be more research active) or patient (eg, wanting to improve the next person's experience).

Expectations should be made clear at the outset, but understanding and trust may develop over time through seeing tangible benefits/gains from the collaborative endeavour. Mutual learning and better appreciation about each other's perspectives and contributions may lead to the potential of both better processes and outcomes through the generation of more relevant, applicable knowledge.

Mutuality within the knowledge endeavour is increasingly more difficult within a multiple communities' perspective. There are a wide range of stakeholders on any given healthcare issue, across patient, family, public, service, charitable and political sectors, some of which may only become apparent through the co-production of knowledge, and over time. Each stakeholder group will bring a different cognitive and emotional representation on that issue, shaped by different experiences and interests. In this sense, a shared understanding of the nature of research and potential contributions to the research process has also to be considered within a dynamic context of different stakeholders' mental models, which can be used to deconstruct and advance the knowledge problem towards potential solutions. The degree to which there has to be agreement and/or traction within this dynamic context is unknown, but may be explored through reflexive analyses of participation within co-production programmes over time.

\section{Architectures to Support Collaborative Action}

Fundamentally, collaborative action will be a function of the quality of relationships, ie, the connection and rapport between relevant stakeholders. Research-service organisational partnerships, such as the Collaborations for Leadership in Applied Health and Care (CLAHRC) in the United Kingdom provide one example of how programme and project level collaborations might be encouraged and facilitated. CLAHRCs, which are funded by the National Institute for Health Research (NIHR), are partnerships between universities and health services, within a regional footprint. The intention of the NIHR was to establish these collaborations in order to accelerate the generation of more applied health research and to enable that research to be applied in practice. Without this funding it is unlikely that these partnerships would have been established $(a)$ at all, and (b) in the timeframe that the funder demanded. Drawing on the findings of an empirical study of CLAHRCs, ${ }^{12}$ connectedness between stakeholders was largely determined by the CLAHRCs' formal governance arrangements. These findings show that the potential for connectivity was mediated by the style of leaders - more or less command and control versus facilitative, which created tighter (less penetrable) versus looser (more open) networks. The organisation of the work within the partnership, such as a thematic structure of clinical and implementation themes, had created silos, and reduced the opportunities for interaction, communication and working together. Dedicated resources in the form of boundary spanners took on roles such as being knowledge brokers and facilitators. These people navigated practice and academic spaces, and also connected different constituencies together. Further, the potential to demonstrate quick wins and impact was dependent on the nature and quality of the existing relationships between stakeholders at the beginning of the collaboration. As such, it is clear from this study along with our experiences of working in or evaluating different models, ${ }^{13}$ that collaboration does not occur in a vacuum or without some prompting or promoting. Equally, it cannot be assumed that either researchers or knowledge users come with the skills and capabilities to be natural collaborators.

\section{Capability and Capacity}

Are there certain types of people or a particular skill set that would make an individual better able or equipped to engage in research-service collaborative research? Given this type of research takes place in the real life world of practice, there are some general transferable qualities that might be embodied in researchers, such as being: able to wear more than one hat (being generalists), comfortable in the field, tolerant of messiness, a good communicator with different audiences, able to go with the flow and be adaptable whilst maintaining the standards of research rigour, able to manage conflict, be tenacious and creative (to name a few). From a knowledge user perspective, understanding that expectations (and thereby constraints) are often set by funders, which defines and confines what can be delivered is equally important. Qualities required of knowledge users may include patience with researchers about the parameters around what is 'good enough' research, and that there is a need for commitment to engage until completion (which for practice, may not feel soon enough). It is also important to acknowledge that framing the research endeavour as a collaborative act may not be compatible with some people's worldview or skill set. Finally, funding to undertake collaborative research requires some commitment to the agenda by funders, including funding 'softer' aspects such as time to build relationships and joint agenda setting.

\section{Not a Panacea}

The growing interest and popularity around more collaborative and co-productive way of framing KT research should be balanced with some of the challenges. This includes asking the question whether all research endeavours lend themselves to this approach. Some might argue, for example, that new drug development does not require collaboration with the eventual drug prescriber. However, perhaps the answer to this question for some would rest on what gets counted as 'science,' although any applied research may also receive the same criticisms (from some) about generalisability, universality, and objectivity. However, there may be research agendas, or incremental and discrete research studies within these agendas, that require partnership but do not need to be collaborative to achieve.

Genuine collaboration through productive relationships takes time to establish and effort to maintain. Competing demands and agendas require effort, which may well not be funded by external agencies, or clearly evident within the array of performance metrics associated with research 
work. Practical challenges arise when, for example, there are changes to personnel which mean that personal connections that have been built up get broken and new relationships need to be established. More generally, mobilising resources to undertake any type of research takes time to establish, by which time, the clinical/service question may have become less relevant or even redundant.

\section{Conclusion}

Ensuring that knowledge from research drives improvements in healthcare with greater urgency and impact requires greater recognition of co-production alongside more traditional, researcher-driven activity. The ontology of co-production emphasises the importance of engaging and integrating the multiple perspectives of stakeholders that can shape the understanding, and processes of knowledge generation and use. Based on relationships between stakeholders, coproduction requires both an organisational and a resource infrastructure, and, therefore, political space to happen. Drawing on our experiences of KT research in Canada, a clinical academic partnership network in Australia, and the CLAHRC programme in National Health Service (NHS) England in particular, we have highlighted some of the features of this infrastructure, and the people working within in it, that might make co-production successful. These include the need for creativity in bringing stakeholders into co-production in a meaningful way through an appreciation of the shared agendas and motivations, and an organisational architecture which allows collaborations, networks and relationships to grow over time.

\section{Ethical issues}

Not applicable.

\section{Competing interests}

The authors declare that they have no competing interests

\section{Authors' contributions}

The ideas for this editorial emerged from a round table discussion between all the authors. JRM did a first draft of the editorial, CB did a further iteration, and then all authors contributed to drafting. All read, and agreed the final version.

\section{Authors' affiliations}

${ }^{1}$ School of Healthcare Sciences, Bangor University, Bangor, UK. ${ }^{2}$ School of Nursing and Midwifery, Deakin University, Geelong, VIC, Australia. ${ }^{3}$ Centre for Nursing Research Monash Health, Melbourne, VIC, Australia. ${ }^{4}$ School of Epidemiology, Public Health and Preventive Medicine \& Ottawa Hospital Research Institute, Ottawa, ON, Canada. ${ }^{5}$ School of Nursing, University of Ottawa, Ottawa, ON, Canada.

\section{References}

1. Greenhalgh $\mathrm{T}$, Wierenga $\mathrm{S}$. Is it time to drop the knowledge translation metaphor? A critical literature review. Journal of Royal Society of Medicine. 2011;104:501-509. doi:10.1258/ jrsm.2011.110285

2. Glasziou P, Altman DG, Bossuyt P, et al. Reducing waste from incomplete or unusable reports of biomedical research. Lancet. 2014;383(9913):267-276. doi:10.1016/s0140-6736(13)62228-x

3. Rycroft-Malone J. From knowing to doing- from the academy to practice. Int $J$ Health Policy Manag. 2014;2(1):45-46. doi:10.15171/ijhpm.2014.08

4. Nowotny H, Scott P, Gibbons M. Rethinking Science: Knowledge in an Age of Uncertainty. Cambridge: Polity Press; 2001.

5. Van de Ven A. Engaged Scholarship: A Guide for Organizational and Social Research. Oxford: Oxford University Press; 2007.

6. Scott A, Skea J, Robinson J, Shove E. Designing 'interactive' environmental research for wider social relevance (Special Briefing No.3). ESRC Global Environmental Change Programme, University of Sussex; 1999

7. Jagosh J, Macaulay AC, Pluye $\mathrm{P}$, et al. Uncovering the benefits of participatory research: implications of a realist review for health research and practice. Milbank Q. 2012;90(2):311-346. doi:10.1111/j.1468-0009.2012.00665.x

8. Strauss SE, Tetroe JM, Graham ID. Knowledge Translation in Healthcare. Chichester: Wiley Blackwell; 2013

9. Graham ID, Tetroe JM, Pearson A, eds. Turning Knowledge into Action: Pratical Guidance on How to Do Integrated Knowledge Translation Research. Wolters Kluwer-Joanna Briggs Institute Synthesis Series in Healthcare. Book 21. Philadelphia; Lippincott, Williams and Wilkins; 2014

10. Armitage D, Berkes F, Dale A, Kocho-Schellenberg E, Patton E. Co-management and the co-production of knowledge: Learning to adapt in Canada's Arctic. Glob Environ Change. 2011;21(3):995-1004. doi:10.1016/j.gloenvcha.2011.04.006

11. Graham ID, Harrison MB, Cerniuk B, Bauer S. A communityresearcher alliance to improve chronic wound care. Healthcare Policy. 2007;2(4):72-78. doi:10.12927/hcpol.2007.18876

12. Rycroft-Malone J, Burton C, Wilkinson J, et al. Collective action for knowledge mobilisation: a realist evaluation of the collaborations for leadership in applied health research and care. Health Serv Deliv Res. 2015;3(44). doi:10.12927/hcpol.2007.18876

13. Bucknall T. Bridging the know-do gap in health care through integrated knowledge translation. Worldviews Evid Based Nurs. 2012;9(4):193-194. doi:10.1111/j.1741-6787.2012.00263.x 